\section{European stem-cell ruling is misleading}

Last month the European Court of Justice ruled that inventions derived from human embryonic stem cells are largely unpatentable. This ruling will shape the development of stemcell technology. So, to prevent confusion, we wish to point out that the ruling contains crucial errors with respect to the underlying science.

At issue is the dividing line between what does and does not constitute an individual human. Under European law, individuals are not patentable. The new ruling misleadingly classifies pseudo-fertilized eggs, or parthenotes (lumping together those made with and without nuclear transfer), as requiring the protections of personhood. This classification was made on the grounds that these eggs are "capable of commencing the process of development of a human being just as an embryo created by fertilization of an ovum can".

However, mammalian parthenogenetic embryos do not develop in the same way as normal embryos; nor are they developmentally viable if made without nuclear transplant. They are far down the sliding scale of developmental potential shared by all cells (including cells in the adult human body). It is therefore misguided for the ruling to put all parthenotederived cells, which have technological potential (see A. A. Kiessling Nature 434, $145 ; 2005)$, at the same end of the scale as cells that can fully differentiate (totipotent cells).

The ruling sensibly prevents a second confusion: inventions derived from human embryonic stem cells that require prior destruction of embryos are, it says, unpatentable. Because the technology already exists to make human embryonic stem-cell lines that preserve the viability of the donor embryo (Y. Chung et al. Cell Stem Cell 2, 113-117; 2008), embryo destruction is unnecessary. The scope of the ruling may therefore be narrower than some might conclude.

Whether one is for or against biological patenting (and we have no settled view or financial interest at stake here), it will be unfortunate if the wording of the European Court's ruling should inadvertently inhibit a potentially useful, ethical technology using parthenotes just because of a lapse in scientific understanding. Jeremy B. A. Green on behalf of 6 co-authors ${ }^{*}$ King’s College London, UK.

jeremy.green@kcl.ac.uk Competing interests declared. See http://dx.doi.org/10.1038/479041a for declaration and ${ }^{\star}$ full author list.

\section{Call to support Greek research reforms}

As members of the Greek National Council for Research and Technology, we appeal to the global scientific community to lend us its support in Greece's present critical economic situation. We must convince governments and relevant international bodies that we need a more realistic time frame to enable Greece to achieve the objectives that we all hold in common.

The council's role is to advise on the reorganization of Greek research as an engine for future growth and as a way out of the current crisis. There is a grave danger, however, that the research infrastructure, and many institutions essential to its upgrading, could disintegrate because of the pressures being placed on the country.

Greece's international creditors are demanding rapid restructuring of the entire research establishment, forcing financial cuts to be made indiscriminately, with serious implications for recovery prospects.

In working to reform the research infrastructure, the council has seen that key stakeholders are determined to put Greece on a more effective track and are enthusiastic about radical change. The Greek scientific community contains pockets of excellence and much talent and dedication. It is imperative that Greece is allowed time to implement the muchneeded reforms in a careful and orderly way.

Stamatios M. Krimigis Academy of Athens, Greece.

Aristides A. N. Patrinos

Synthetic Genomics, La Jolla, California, USA.

apatrin@syntheticgenomics.com

\section{Easter Island's complex history}

The history of Easter Island is important because it offers a lesson in long-term survival in an isolated and resource-poor environment. In his review of our book, The Statues That Walked, Paul Bahn makes some potentially misleading assertions (Nature 476, 150-151; 2011).

He implies that we have overlooked other people's work, but those studies are unpublished. We instead acquired our own data, controlling for content and quality.

Our excavations and radiocarbon dating indicate that Easter Island was colonized several centuries later than Bahn contends (T. L. Hunt and C. P. Lipo Science 311, 1603-1606; 2006). Settlement of this and other islands in eastern Polynesia occurred over the past 800-1,000 years. On the basis of new evidence, most archaeologists working on Easter Island now reject the notion that its population collapsed before the arrival of Europeans.

It is generally agreed that the island was almost completely deforested by the time Europeans arrived in 1722 . We never argued that rats were the only cause of deforestation, which happened over centuries and resulted from people burning vegetation for agriculture, and from rat predation of seeds.

Although there is skeletal evidence for some violence on the island, only a few examples indicate mortal wounding. As we explain in our book, the statues were a focus of competitive signalling that staved off lethal violence.

Terry L. Hunt University of Hawaii-Manoa, Honolulu,

Hawaii, USA.

thunt@hawaii.edu

Carl P. Lipo California State

University, Long Beach,

California, USA.

\section{Control of dengue fever in Pakistan}

Five years ago the Indian subcontinent experienced its first epidemic of dengue fever, with more than 5,000 people in India and more than 2,000 in Pakistan hospitalized (M. A. Rai and H. Khan J. Clin. Virol. 38, 269-270; 2007). Pakistan is now in the middle of a dengue resurgence: more than 15,000 cases have been recorded in Lahore alone. This is potentially disastrous for the country's health-care system, which is already on its knees.

Mortality is much higher this time. There have also been reports in Pakistan of resistance to agrochemicals evolving in dengue mosquitoes (H. A. Khan et al. Parasite Vectors 4, 146; 2011), calling into question the current massive fumigation drive. Last year's record floods have aggravated the situation.

Dengue experts have been flown in from Sri Lanka, Indonesia and the World Health Organization, but they may be too late. Prior planning and policy formulation by Pakistan's health-care authorities are key to the prevention of future dengue outbreaks.

Mohammad A. Rai Nuffield Department of Medicine, University of Oxford, UK. mohammad.rai@ndm.ox.ac.uk 